\title{
INSTITUIÇÕES DE ENSINO SUPERIOR FUNDACIONAIS DO ESTADO DE SANTA CATARINA: COMPROMISSOS COM O DESENVOLVIMENTO REGIONAL
}

\section{FOUNDATIONAL INSTITUTIONS OF HIGHER EDUCATION IN SANTA CATARINA STATE: COMMITMENTS FOR THE REGIONAL DEVELOPMENT}

\section{Argos Gumbowaky ${ }^{1}$}

Resumo: O artigo objetiva apresentar aspectos relevantes da evolução das Instituições de Ensino Superior Fundacionais Municipais no estado de Santa Catarina, que almejava, na sua gênese, contribuir para o desenvolvimento regional. Discute-se, ainda, o conflito entre o seu compromisso original de fomentar o desenvolvimento regional, transitando por um período de mercantilização do ensino superior e, mais recentemente, convivendo com políticas públicas que ampliam o acesso ao ensino superior gratuito. Quanto à metodologia da pesquisa adotada, assume características de pesquisa documental, bibliográfica e histórica. Na primeira década do século XXI, políticas públicas ampliaram a oferta de cursos e vagas gratuitas, gerando novos desafios para sua sobrevivência e cumprimento do seu compromisso primeiro, isto é, promover o desenvolvimento regional.

Palavras-chave: desenvolvimento regional; ensino superior municipal; políticas públicas.

Abstract: The article aims to present relevant evolutional aspects of Foundational Institutions of Higher Education from Santa Catarina, which had in their genesis to contribute to regional development. The conflict between their original commitments of promoting the regional development is discussed, passing through the commodification of higher education and, more recently, living with public policies that expand the access to free higher education. The methodology used assumes bibliographic, documental, and historical research. In the first decade of twenty-first century, public policies expand the courses and free vacancies, generating new challenges for the survival and achievement of their first commitment, which is to promote regional development.

Keywords: regional development; higher and municipal education; public policies.

\footnotetext{
1 Doutor em Educação - Universidade Federal do Rio Grande do Sul - UFRGS, Brasil e Docente da Universidade do Contestado - UnC, Brasil. E-mail: g.argos@brturbo.com.br.
} 


\section{INTRODUÇÃO}

O presente artigo objetiva apresentar aspectos relevantes da evolução das Instituições de Ensino Superior Fundacionais Municipais, no estado de Santa Catarina, Brasil, que almejava, na sua gênese, contribuir para o desenvolvimento regional.

No ano de 2010, o estado de Santa Catarina contava com uma população de 6.248.436 habitantes, dos quais 80\% residem na área urbana, distribuídos em 295 municípios. Nesse ano, o Índice de Desenvolvimento Humano (IDH) do estado era 0,840, ficando em segundo lugar, dentre as demais unidades da federação, enquanto o Brasil apresentou índice de 0,699.

Estudo realizado pelo Serviço de Apoio às Micro e Pequena Empresas de Santa Catarina - Sebrae, em 2010, indicou que a distribuição populacional por gênero era constituída por $50,2 \%$ de mulheres e $49,8 \%$ de homens. Os jovens representavam 33,7\% da população, os adultos $56,5 \%$, e os idosos, $9,8 \%$. Dados da Federação das Indústrias de Santa Catarina (Fiesc), de 2012, indicam que o Produto Interno Bruto (PIB) catarinense ocupava a oitava colocação no Brasil, registrando, em 2009, $\mathrm{R} \$ 129,8$ bilhões. O setor secundário participava com $32,8 \%$, o terciário com $59,0 \%$, e o primário com $8,2 \%$. O estado é o maior produtor nacional de cebola e maçã; o segundo maior no cultivo de arroz e fumo; e o terceiro de alho e banana. Detém o maior rebanho nacional de suínos e o segundo de frangos.

O estado de Santa Catarina, a partir do ano de 2003 foi dividido em 36 Secretarias de Desenvolvimento Regionais (SDR), com o objetivo de interiorizar as ações do governo e estimular o desenvolvimento econômico e social, dentre outros.

No campo educacional, em 2010, o índice de analfabetismo era de 3,86\%, sendo a média nacional de 9\%. Em 2011, a média do Índice de Desenvolvimento da Educação Básica (Ideb) alcançado pelo estado foi de 5,7 para os anos iniciais do ensino fundamental e 4,7 para os anos finais; o ensino médio atingiu 4,0. Entre os estados brasileiros, Santa Catarina, também, destacou-se na avaliação do Programa Internacional de Avaliação de Alunos (PISA), de 2009, obtendo 428 pontos, representando o segundo lugar no país, enquanto a pontuação nacional chegou a 401. O censo de 2010 apontou que $24 \%$ da população possui ensino superior completo, o que significa o dobro da média nacional. Mesmo detentor de tais índices, o estado possui, em seu território, situação heterogênea quanto ao desenvolvimento regional.

O Art. 45 da Lei Federal n. 9394/96 estabelece que "A educação superior será ministrada em instituições de ensino superior, públicas ou privadas, com variados graus de abrangência ou especialização". Extrapolando a dicotomia público X privado, o estado caracteriza-se por Instituições de Ensino Superior (IES) comunitárias. Estas são confundidas ora como privadas, ora como públicas.

Até o ano de 2009, o estado possuía uma universidade mantida pela união, a Universidade Federal de Santa Catarina (UFSC), com sede em Florianópolis, e uma universidade mantida pelo poder público estadual, a Universidade para o Desenvolvimento do Estado de Santa Catarina (UDESC), com sede em Florianópolis, com características multicampi. Diante dessa situação, criou-se um modelo com características singulares, ou 
seja, instituições criadas pela iniciativa do poder público municipal. Esse sistema possui como características:

Forte espírito comunitário, delineado através da presença do poder público municipal no apoio ao desenvolvimento das atividades de cada instituição, da colaboração estreita com a empresa privada e do volume de bolsas de estudo concedidas aos seus alunos. - Intensiva procura de soluções próprias, alicerçada em iniciativas individuais ou de grupos organizados, em função de necessidades e interesses locais ou regionais, com aproveitamento pleno do potencial de cada instituição em relação ao seu meio. - Grande capacidade de antecipação e de reação diante dos desafios locais, regionais e nacionais, fortalecida tanto pelas tradições de origem de cada instituição quanto pela diversificação dos modelos gerenciais adotados, além de uma constante preocupação com a sobrevivência de cada empreendimento em função dos objetivos societários e econômicos das microrregiões em que atuam (ASSOCIAÇÃO CATARINENSE DAS FUNDAÇÕES EDUCACIONAIS, 1999, p. 7).

Durante mais de quarenta anos, esse modelo de ensino superior contribuiu para a oferta de vagas no nível de ensino superior. Conviveu sem a presença da competição das IES privadas, uma vez que, até a década de 1990, havia apenas uma instituição e que não chegava a ameaçar a hegemonia das IES municipais.

A não presença de IES privadas foi consequência do poder de articulação das IES municipais, as quais, reunidas na Associação Catarinense das Fundações Educacionais (ACAFE), fizeram valer a sua força política, dificultando a invasão de IES privadas, cujo principal objetivo é o lucro. Entretanto, a promulgação da Lei de Diretrizes e Bases da Educação Nacional, Lei Federal n 9.394/96 e a política de distanciamento do poder público no desenvolvimento e aperfeiçoamento do ensino superior, com o consequente estímulo para que a iniciativa privada assumisse o espaço anteriormente ocupado pelo poder público, gerouse o aumento das IES privadas no estado de Santa Catarina. Já, na primeira década do século XXI, além da expansão das IES privadas, o governo federal passou a ampliar o número de universidades estatais, o que muito bem poderia ter ocorrido em parceria com as IES já existentes, fundacionais e de cunho comunitário. No ano de 2009 , foi criada a segunda IES pública federal: a Universidade Federal da Fronteira Sul (UFFS), com sede na cidade de Chapecó, no oeste do estado, e com características multi campi nos estados do Paraná e Rio Grande do Sul. Também, alguns municípios passaram a criar IES: em 2005 foram criados o Centro Universitário Municipal de São José (USJ), e a Faculdade Municipal de Palhoça (FMP), ambas públicas gratuitas.

A metodologia adotada, nesta pesquisa, assume características de pesquisa documental. Foram consultados documentos institucionais: leis, projetos, regulamentos, registros de cartório, instrumentos de comunicação institucionais, dentre outros.

Buscou-se em bibliografias, na legislação educacional, dentre outros, subsídios teóricos e fundamentos que permitiram a compreensão, pormenorizada, das razões que motivaram as suas criações. A pesquisa, também, procurou articular-se com os princípios da pesquisa histórica por produzir um registro fiel do passado, e contribuir para solução de problemas atuais (RICHARDSON, 1999). 
As fontes de pesquisa foram de duas naturezas: primárias e secundárias.

\section{O IMPACTO LOCAL E REGIONAL DAS UNIVERSIDADES}

No âmbito da legislação de ensino, o artigo 43 da Lei Federal n. 9.394/96 ao definir as finalidades do ensino superior, estabelece princípios que podem ser considerados determinantes para o desenvolvimento regional.

A partir desses princípios, a existência de uma instituição de ensino superior pressupõe a existência de elementos que contribuam para a promoção do desenvolvimento regional, respeitada sua escala e articulação com a sociedade.

O ensino superior conta com um conjunto diversificado de instituições (universidade, centro universitário e faculdade); contudo, são as universidades que cumprem as funções atribuídas pela Constituição: ensino, pesquisa e extensão, cujo compromisso está na superação das desigualdades sociais e regionais. Valente enfatiza que "esse núcleo estratégico tem como missão contribuir para o desenvolvimento do país e a redução dos desequilíbrios regionais, nos marcos de um projeto nacional” (VALENTE, 2001, p. 96).

Considerando a importância do ensino superior para o desenvolvimento, um dos pontos nevrálgicos está no acesso a esse segmento educaional. A média brasileira de jovens na faixa etária de 18 a 24 anos, matriculada no ensino superior, segundo a Pesquisa Nacional por Amostra de Domicílio (PNAD), realizada em 2009, é de 19\%. O percentual brasileiro é baixo quando comparado ao de países, como, por exemplo, França, Espanha e o Reino Unido, onde o índice é superior a 50\%, ou, ainda, em relação ao de algumas nações da América Latina, como o Chile (52\%).

Dentre as várias políticas definidas pela Lei Federal n. 10.172/2001, que aprovou o Plano Nacional de Educação (PNE) 2001-2010, estava a reversão desse quadro. Dentre os objetivos e metas envolvendo o período compreendido entre 2000 e 2010, estava a ampliação para $30 \%$ da oferta de ensino superior, abrangendo a faixa etária de 18 a 24 anos e o estabelecimento de "uma política de expansão que diminua as desigualdades de oferta existentes entre as diferentes regiões do país" (VALENTE, 2001, p. 98). Esse percentual não foi alcançado. Com a aprovação do PNE 2014-2024, pela Lei Federal 13.005/2014, a meta 12 estabelece:

[...] elevar a taxa bruta de matrícula na educação superior para 50\% (cinquenta por cento) e a taxa líquida para 33\% (trinta e três por cento) da população de 18 (dezoito) a 24 (vinte e quatro) anos, assegurada a qualidade da oferta e expansão para, pelo menos, $40 \%$ (quarenta por cento) das novas matrículas, no segmento público.

Com objetivo de reverter o quadro de desigualdades da educação superior no Brasil, nos últimos anos, algumas medidas estão sendo implementadas, dentre as quais se destacam:

a) Ampliação de vagas: até o ano de 2003 foram criadas 45 IES federais. No período 
2003-2010 foram criadas 14 novas IES federais, totalizando 59, com previsão desse número chegar a 63 , em 2014, também foram criados mais de 100 novos campi que possibilitaram a ampliação de vagas e a criação de novos cursos de graduação. Paralelamente, foi criado o Programa de Apoio a Planos de Estruturação e Expansão das Universidades Federais (Reuni). O artigo 1․ do Decreto Federal n. 6.096/2007 estabelece, como objetivo, "criar condições para a ampliação do acesso e permanência na educação superior, no nível de graduação, pelo melhor aproveitamento da estrutura física e de recursos humanos existentes nas universidades federais". Entre 2006 a 2012, a meta era dobrar o número de vagas nas universidades públicas brasileiras, passando de 600 mil para 1,2 milhão. O investimento, para o alcance dessa meta, seria de cerca de $R \$ 4$ bilhões em infraestrutura. Segundo relatório da Associação Nacional dos Dirigentes das Instituições Federais de Ensino Superior (ANDIFES), tendo 2007 como ano de referência do Reuni, as universidades federais aumentaram em $49 \%$ a oferta de vagas nos cursos de graduação, com 65.306 novas vagas até 2010. Em paralelo, o número de cursos aumentou de 2.190 em 2006 para 3.225, em 2010. Destaque é dado à expansão dos cursos noturnos, que, em 2006, eram 645 e até 2010 somaram 1.129, configurando crescimento de 75\%; e das licenciaturas, cujo aumento da oferta chega a 43\%, com 1.099 cursos, em 2010, ante 767 em 2006.

b) Interiorização: historicamente a educação superior estatal concentrou-se nos grandes centros urbanos. A expansão da Rede Federal de Educação Superior, a partir de 2003, ocorreu com a interiorização dos campi das universidades federais. Com isso, o número de municípios atendidos pelas universidades passou de 114, em 2003, para 237, no final de 2011.

c) Ampliação do financiamento aos estudantes: para atender a esse objetivo, foram criados programas, como o Programa Universidade para Todos (Prouni) e a reedição do Fundo de Financiamento ao Estudante de Ensino Superior (Fies). Os dois agentes financeiros do Fies, o Banco do Brasil e a Caixa Econômica Federal haviam promovido a assinatura de 760 mil contratos, com um investimento total, aproximado, de $R \$ 25$ bilhões até o fim de 2012 . Já, o Prouni disponibilizou, entre 2005-2012, 1.667 .938 bolsas.

d) Estímulo à modalidade de Educação a Distância: por meio de parcerias com IES estatais mantidas pelo governo federal, com IES estaduais e municipais foi criada a Universidade Aberta do Brasil (UAB). Em outubro de 2012, a Coordenação de Aperfeiçoamento de Pessoal de Nível Superior (CAPES, 2013) informou que a UAB possuía mais de 160 mil alunos matriculados em cursos de graduação, sendo 140 mil em cursos de licenciaturas, 24.207 em bacharelados e 6.877 em cursos superiores de tecnologia, além de cursos de especialização, extensão e pós-graduação. Para atender a essa demanda, a UAB está presente em, aproximadamente, 600 municípios, contando com a parceria das instituições públicas de ensino superior (IPES). Vinculadas ao programa estão 103 Ipes, sendo 56 universidades federais, 30 estaduais e 17 institutos federais de educação, ciência e tecnologia.

e) Implementação de Políticas e Programas de Inclusão e de Ações Afirmativas. Destaca-se a política de cotas adotada por várias universidades, bem como, a adequação da 
estrutura física, permitindo a inclusão de pessoas com necessidades especiais. Em agosto de 2012, foi promulgada a Lei Federal n. 12.711, definindo que as IES públicas federais deverão reservar $50 \%$ de suas vagas para estudantes que estejam cursando, integralmente, o ensino médio em escolas públicas, sendo que desse percentual, $50 \%$ das vagas deverão ser destinadas a estudantes com renda familiar igual ou inferior a 1,5 salário mínimo.

Tanto maior será a contribuição da universidade para a sociedade quanto for a sua inserção regional. Nesse sentido, além da sua condição de Universidade, a instituição deve assumir características de universidade regional, articulando-se com os vários municípios ao seu entorno.

Caracteriza-se como instituição regional por estar em constante diálogo com a comunidade, atendendo as suas necessidades e constituindo-se em fator de integração a partir de cada realidade, buscando um projeto coletivo de desenvolvimento e um crescimento harmônico da região em que atua. A universidade regional tem como responsabilidade social a sua contribuição na promoção e articulação 'da e entre' as comunidades, em função das demandas que se apresentam, procurando catalisar iniciativas e ações voltadas para o desenvolvimento da região (LAUXEN, 2006, p. 238).

A instalação de universidades pode indicar e ou explicar o crescimento de determinados países, estados ou regiões.

A transferência de tecnologia constitui-se em uma das principais atividades de ligação entre o interior da universidade e o mundo externo. Mas esse processo não ocorre de modo homogêneo em todos os locais. A aproximação entre grandes empresas e cientistas ocorre com maior frequência, ao contrário de pequenas empresas locais.

Goddard (1998, p.404) registra que "as subvenções e os contratos de pesquisa com a interveniência dos parceiros industriais constituem mecanismos importantes. No conjunto, as universidades situadas nas regiões mais prósperas são as que tiram benefícios mais elevados dessas fontes".

No que se refere à missão de pesquisa que cabe às universidades, a importância que a política científica atribui à criação de riquezas por meio de ligações com a indústria, e a pressão dos poderes públicos para que as instituições de ensino superior concretizem medidas de colaboração, fortaleceram os argumentos em favor da atividade regional no espírito dos quadros superiores da universidade (GODDARD, 1998, p.417).

Ao analisar o aspecto econômico do impacto da universidade no âmbito local e regional, percebe-se que as universidades são empregadoras de contingente de pessoal de nível relativamente elevado, com salários acima da média, dependendo da região, os quais acabam tendo poder de compra acima da média, contribuindo para o movimento da economia local. Pode-se questionar que muitos não são recrutados no âmbito local, mas a estrutura intermediária certamente o é. Também, os estudantes exercem influência na economia local à medida que são consumidores.

Várias pesquisas indicam que a ampliação da escolaridade confere poder econômico aos egressos.

Revista Univap - revista.univap.br

São José dos Campos-SP-Brasil, v. 20, n. 36, dez.2014. ISSN 2237-1753 
De acordo com o trabalho da organização internacional, na média dos paísesmembros da OCDE uma pessoa com grau universitário pode esperar ganhar pouco mais de $50 \%$ do que alguém que só tenha completado o ensino médio. No Brasil, essa expectativa é de mais de $150 \%$, chegando a $164 \%$ para os profissionais mais experientes, na faixa de 55 a 64 anos de idade (ORCl, 2013).

Finalmente, deve-se avaliar a universidade por intermédio de sua contribuição no desenvolvimento social e comunitário. Para Diniz:

A atuação e a função social das instituições de ensino superior não ficam mais restritas à sala de aula. Estão ganhando as ruas em projetos e ações que transformam realidades e apontam novas opções de futuro, com o aval e a participação, muitas vezes voluntária, dos alunos. O conceito que está por trás dessa transformação é o de responsabilidade social, as chamadas 'ações conscientes', que respeitam as necessidades do meio ambiente e da comunidade (DINIZ, 2009, p. 40).

Algumas pessoas consideram que o aumento das atividades comerciais gerado pelo consumo de alunos, docentes, funcionários; a prestação de serviço ou o aumento da construção civil e dos negócios imobiliários pode constituir-se numa contribuição da universidade para o desenvolvimento regional ou local.

Zöllner (2003) considera que a maior contribuição da universidade para o desenvolvimento local/regional está na formação de quadros técnicos e profissionais que possam contribuir para a melhoria da qualidade de vida dos habitantes da região de sua influência.

Mas, certamente, é por meio do ensino e do recrutamento de seus egressos pelos diferentes segmentos econômicos que se observa maior impacto.

É nesse momento, também, que se destaca a articulação entre ensino, pesquisa e extensão. Por intermédio do ensino, a universidade cumpre o papel de transmissora de conhecimento, mas esse conhecimento é produzido por meio da pesquisa. O conhecimento necessita ser socialmente produzido e possuir sentido para a sociedade onde é produzido e para a qual é destinado.

Assim, a pesquisa precisa estar atenta às problemáticas locais. Além da articulação ensino-pesquisa, esse conhecimento necessita extrapolar os espaços da universidade, chegando aos segmentos da sociedade que não têm a oportunidade de acessá-la, aí a extensão passa a constituir-se em um diferencial.

Assim, quanto maior o grau de interdependência entre essas três dimensões, maior a contribuição da universidade para o desenvolvimento da sociedade. A socialização do conhecimento não é só um dever, mas um determinante forte quando se pretende que a universidade seja democrática, moderna (ZÖLLNER, 2003).

Os países desenvolvidos possuem, como uma de suas características, a participação ativa da universidade como um dos pilares de sustentação do desenvolvimento econômico, social e cultural. Ao longo de sua evolução, a sociedade atribuiu à universidade o papel de 
instrumento de desenvolvimento e progresso. Países cuja articulação universidade e sociedade consolidou-se e onde esta última soube apropriar-se das potencialidades da primeira, cresceram e se fortaleceram no cenário internacional.

A interação da universidade com o setor público, a iniciativa privada, e a sociedade, fazse presente por meio do aumento de vagas de cursos de graduação e pós-graduação atendendo os anseios locais/regionais; formação de recursos humanos; estímulo à interação universidade-empresa; intensificação de pesquisas em áreas estratégicas do desenvolvimento regional; ampliação das atividades de extensão.

A contribuição da universidade, para o desenvolvimento, faz-se presente, também, por intermédio de ações que, muitas vezes, não são mensuradas: a organização de conferências, cujos temas vinculam-se às necessidades da comunidade local; o acesso pela comunidade às bibliotecas, cujos acervos são os mais expressivos e atualizados em cada região. A contribuição para a vida cultural da região não pode ser relegada a segundo plano, principalmente nas cidades de menor porte, cujas atividades culturais são limitadas, ao contrário dos grandes centros urbanos. Vinculados às atividades culturais estão as exposições de obras de arte e o incentivo à preservação do patrimônio cultural, por exemplo.

A prestação de serviços à comunidade é vinculada às atividades obrigatórias dos Projetos pedagógicos de Cursos ou ocorre por iniciativas de Programas Institucionalizados. A participação da comunidade acadêmica, utilizando-se dos espaços disponibilizados pela mídia local, não pode ser esquecida. Como afirma Goddard (1998, p.411), "Através de suas publicações, seus comentários nos meios de comunicação [...], as universidades contribuem para informar as comunidades locais e para fazê-las tomar consciência de si próprias".

Uma atividade não institucionalizada nas universidades é o serviço voluntário de estudantes que promove maior vínculo destes junto à população local.

Goddard destaca:

A experiência americana mostrou o interesse de que se reveste a utilização de voluntários a serviço da comunidade local; os estudantes adquirem assim uma formação e competências que poderão utilizar depois para a resolução de problemas e a negociação. Essa' educação para a cidadania' aproxima as necessidades da comunidade da missão educativa da universidade (GODDARD, 1998, p. 409).

É importante lembrar que as políticas institucionais são aprovadas por colegiados superiores no âmbito da universidade. Dentre essas políticas, está a maior ou menor articulação com programas que visem o desenvolvimento regional. A sociedade possui assento nesses colegiados, daí a necessidade de participação efetiva para aportar aos colegiados as necessidades da comunidade local.

$\mathrm{Na}$ atividade de ensino, não basta a ampliação do número de vagas por cursos. $\mathrm{A}$ preocupação deve centrar-se, também, na aderência das matrizes curriculares às necessidades locais. Um currículo adequado às necessidades locais auxilia a inserção dos egressos no mercado de trabalho, além da criação de estímulo para o retorno dos formados 
à universidade, buscando a formação profissional permanente. Entretanto, essa política encontra resistências e limitações.

[....] os fatores que freiam o crescimento do papel regional compreendem principalmente a insuficiência da demanda de cursos pertinentes para a região por parte dos estudantes [...], a limitação do número de estudantes, o que obriga as universidades a se aterem ao ensino tradicional, a ausência de estratégias regionais de valorização de recursos humanos que permitam orientar o planejamento dos cursos, o fato de as universidades que organizam seus cursos de curta duração ou um ensino de nível inferior aos bacharelado não serem recompensadas, o papel das organizações nacionais de habilitação profissional, os critérios nacionais de avaliação da qualidade do ensino, o fato de a universidade ter poucos contatos com o sistema de formação regional em nível inferior aos quadros superiores (GODDARD, 1998, p. 417).

Um aspecto positivo da criação de cursos superiores nas diversas áreas do conhecimento está no fato de estancar parte do êxodo de estudantes para centros urbanos maiores, dos quais poucos retornam para suas cidades de origem. Há, aí, uma evasão de profissionais qualificados que poderiam contribuir para o desenvolvimento de suas localidades.

Quando da escolha da universidade pelos estudantes, fatores geográficos, como a localização da cidade acabam tendo peso similar ao curso pretendido. A pujança econômica do local onde a universidade está inserida representa para ela um forte apelo para sua contribuição para o desenvolvimento dessa região.

A qualidade de uma universidade, também, é determinante para o desenvolvimento regional. No caso brasileiro, políticas com objetivo de melhorar a qualidade do ensino ministrado nas universidades constituem-se em fatores de redução das deficiências regionais. A promulgação da Lei Federal n. 10.861/2004 estabeleceu o Sistema Nacional de Avaliação da Educação Superior (SINAES). Essa lei instituiu a avaliação em três níveis: a) Avaliação de Instituições; b) Avaliação de Cursos de Graduação; c) Exame Nacional de Avaliação do Desempenho dos Estudantes (Enade).

Possuindo a universidade uma estrutura de gestão relativamente flexível, a tomada de decisão quanto à priorização de projetos de ensino, pesquisa e extensão pode gerar seus efeitos, na região, a partir das suas prioridades estabelecidas. Por outro lado, também, as instituições regionais podem não demonstrar, de modo claro, à universidade as necessidades da região, principalmente àqueles docentes cuja incumbência está na aplicação dos programas de ensino, pesquisa e extensão. A falta de entrosamento da universidade com a sociedade pode trazer prejuízos significativos para ambas as partes.

Assinala Goddard (1998) que as universidades devem estabelecer diálogo com os diferentes segmentos responsáveis pelo desenvolvimento regional e as administrações centrais, das quais dependem o financiamento do ensino superior; as autoridades eleitas locais e regionais; os empregadores e as organizações patronais; as organizações culturais; os meios de comunicação regionais; os níveis inferiores do sistema educativo; e os recém diplomados e os estudantes atuais e futuros. Enfatiza Goddard que: 
[...] não será através de mecanismos de planejamento que operam de cima para baixo em escala institucional ou regional que se poderá melhorar a integração das universidades no desenvolvimento regional, mas fazendo com que os diversos atores do processo de desenvolvimento regional educadores e formadores, empregadores e organizações patronais, sindicatos, organizações encarregadas do desenvolvimento econômico e do mercado de trabalho, assim como professores e estudantes tomados individualmente - tenham uma compreensão mútua de seus respectivos papéis e dos fatores que favorecem ou que dificultam o avanço do engajamento regional (GODDARD, 1998, p. 398).

Almeida considera que "a universidade exerce funções básicas de reproduzir e de criar. Desenvolvimento é criação, produção de novas formas, de novas relações de produção" (1980, p. 32). No seu entendimento, reprodução não é desenvolvimento. Contudo, numa região carente de conhecimento, a transferência e apreensão do conhecimento universal pode contribuir para estimular o desenvolvimento, desde que desperte atitudes de autonomia e não de dependência.

A valorização e a preservação da cultura regional constituem-se em elementos de desenvolvimento regional. "Desenvolvimento é transformação, mas não descaracterização, perda de personalidade, abandono dos valores básicos" (ALMEIDA, 1980, p. 33).

As universidades regionais possuem articulações entre si, no âmbito nacional e internacional, o que, em muito, pode contribuir para as empresas locais e para os estudantes.

Numa perspectiva regional, pode-se citar o modelo das universidades comunitárias gaúchas e o Sistema Fundacional Municipal Catarinense. O modelo fundacional catarinense, quando da sua criação, objetivava à participação ativa no processo de desenvolvimento regional ou ser um determinante nesse desenvolvimento.

\section{O SISTEMA MUNICIPAL FUNDACIONAL CATARINENSE: UM EXEMPLO DE CONTRIBUIÇÃO DA UNIVERSIDADE PARA O DESENVOLVIMENTO REGIONAL}

Independentemente da ação dos governos federal ou estadual, fundações educacionais foram criadas a partir da década de 1960, com estrutura administrativa e financeira próprias - em todos os casos, com o aval dos municípios - públicas, portanto - com forte apoio financeiro. Essa iniciativa, além de atender aos anseios locais quanto à ampliação do número de vagas no ensino superior, encontrava respaldo da legislação da época.

A Lei Federal $n^{\circ} 4.024 / 61$, em seu artigo 107, concedeu estímulo às fundações educacionais ao mencionar que:

O poder público estimulará a colaboração popular em favor das fundações e instituições culturais e educativas de qualquer espécie, grau ou nível sem finalidades lucrativas, e facultará aos contribuintes do imposto de renda a redução dos auxílios ou doações comprovadamente feitos a tais entidades (BRASIL, 1961).

A Lei Federal $n^{\circ} 5.540 / 68$, no seu artigo $2^{\circ}$, dispõe que "o ensino superior indissociável 
da pesquisa será ministrado em universidades e, excepcionalmente, em estabelecimentos isolados, organizados como instituições de direito público ou privado".

Apesar das Leis Federais $n^{\circ}$ 4.024/61 e $n^{\circ}$ 5.540/68, que estabeleceram a reforma universitária, determinarem que o ensino superior fosse ministrado em universidades, no contexto catarinense, o que prevaleceu foi a exceção, ou seja, a proliferação de instituições isoladas de ensino superior. Frente a esse contexto, começaram a se delinear as primeiras iniciativas com vistas à criação de instituições de ensino superior isoladas em Santa Catarina.

Esse processo teve início em 1964, desencadeando iniciativas irreversíveis de:

a) interiorização da oferta de ensino superior;

b) democratização das oportunidades de acesso a cursos superiores de formação profissional;

c) formação de quadros vocacionados para o atendimento das necessidades locais;

d) constituição de um corpo de professores capacitado, selecionado segundo os critérios exigidos pelo Conselho Federal de Educação;

e) instalação de uma infraestrutura de ensino qualificada; e

f) disseminação, por todo o Estado, de equipamentos laboratoriais e de bibliotecas especializadas.

A interiorização do ensino superior procurou oportunizar a democratização do acesso a esse grau de ensino. Historicamente, o ensino superior tem se concentrado nos principais polos econômicos, principalmente nas capitais, centralizando o desenvolvimento e a tecnologia em detrimento das regiões interioranas dos estados. Não se podem desconsiderar os interesses políticos das lideranças locais, pois estas eram cientes de que a criação de uma instituição de ensino superior Ihes traria ganhos políticos.

[...] o modelo de Ensino Superior Catarinense não foi forjado ou criado para ser instrumento de modificação de estrutura social. Pelo contrário, foi a estrutura organizacional do Estado, através das lideranças dos polos regionais, que forjou a instalação de um modelo [...]. Embora com reticências iniciais do Conselho nos pedidos, foi se instalando uma larga visão da necessidade da expansão do Ensino Superior como forma de possibilitar o acesso universitário aos jovens das cidades-polo do Estado, como uma forma de melhoria da qualificação da mão-de-obra face ao avanço tecnológico que já se instalara (CIMADON; BRANCHER, 1992, pp. 64-5).

Mas, por outro lado, não somente de variáveis negativas apresentava-se o sistema fundacional. "Outro aspecto importante é o decisivo papel do sistema fundacional no desenvolvimento cultural, econômico e social nas comunidades do interior, que permitiram, através da democratização das oportunidades, a fixação da mão-de-obra especializada no interior e evitou a concentração da disputa de vagas na capital" (SANTA CATARINA, 1980, p. 87).

A realidade do ensino superior catarinense pode ser demonstrada quanto ao número de 
matriculados no ensino de graduação, entre 1995 a 2010, nas IES municipais. No ano de 1995, estas respondiam por 64.201 matrículas; em 2000, por 118.059 matrículas; em 2005, por 125.724; em 2010, por 119.870 matriculados. Esses números parecerem alvissareiros, mas devemos considerar que as IES privadas apresentaram, nesse período, extraordinário crescimento.

Relatório patrocinado pela Organização para Cooperação e Desenvolvimento Econômico (OCDE) indicou que, em Santa Catarina, no ano de " 2008 , apenas $5 \%$ do total de estudantes eram oriundos da percentagem de famílias mais pobres e que quase todos iam para instituições privadas. Ao contrário, $57,6 \%$ dos estudantes vinham do quintil mais alto. Mais de $90 \%$ dos estudantes das universidades públicas vinham da percentagem de $40 \%$ de famílias ricas, e quase três quartos dos $20 \%$, das mais ricas" (ORGANIZAÇÃO PARA COOPERAÇÃO E DESENVOLVIMENTO ECONÔMICO, 2010, p. 274).

Nas décadas de 1960 e 1970, em Santa Catarina, haviam sido criadas dezessete fundações educacionais pelos poderes públicos, sendo uma pelo Governo Estadual e as demais pelas prefeituras municipais. Desse conjunto, muitas delas transformaram-se em universidades, a partir da segunda metade da década de 1980.

Outro fenômeno que se observa, no cenário educacional catarinense, é a proliferação de entidades estritamente privadas de ensino superior. Durante décadas, Santa Catarina possuía apenas uma entidade considerada privada. Em 2013, são 78 IES privadas explorando esse mercado, certamente muito mais preocupadas com o lucro do que com 0 desenvolvimento regional. É a mercantilização do ensino superior.

Nas origens do sistema educacional fundacional superior catarinense, encontram-se na condição de IES reconhecidas, as seguintes: Universidade do Vale do Itajaí (Univali); Universidade Regional de Blumenau (FURB); Universidade do Sul de Santa Catarina (Unisul); Universidade do Extremo-Sul Catarinense (Unesc); Universidade da Região de Joinville (Univille); Universidade do Oeste de Santa Catarina (Unoesc) [fruto da fusão da Fundação Educacional do Oeste Catarinense (Fuoc) e Fundação Educacional Empresarial do Alto Vale do Rio do Peixe (Femarp)]; Universidade do Contestado (UnC) [constituída pela união de quatro fundações: Fundação Educacional do Planalto Central Catarinense (Feplac) , Fundação das Escolas do Planalto Norte Catarinense (Funploc), Fundação Educacional do Alto Uruguai Catarinense (Feauc), Fundação Universidade do Planalto Norte Catarinense (Funorte)]; Universidade do Alto Vale do Rio do Peixe (Uniarpe); Universidade do Planalto Catarinense (Uniplac); Universidade Comunitária Regional de Chapecó (Unochapecó). Quatro instituições isoladas constituíram-se na modalidade de centro universitário: Centro universitário para o Desenvolvimento do Alto Vale do Itajaí (Unidavi); Centro Universitário de Brusque (Unifebe), Centro Universitário - Católico de Santa Catarina mantida pela Fundação Educacional Regional Jaraguaense (Ferj); e Centro Universitário Barriga Verde (Unibave).

As primeiras décadas de sua existência foram marcadas por crises que assolaram as Fundações Educacionais, marcadas por dependência administrativa do poder público municipal e carência de corpo docente habilitado. O processo de interiorização se deu, 
prioritariamente, em cidades litorâneas, distorção na criação de cursos por área de conhecimento, infraestrutura precária, vagas ociosas, falta de apoio financeiro e técnico.

Hawerroth (1999) identificou, em suas pesquisas, o compromisso das instituições fundacionais com o desenvolvimento de suas respectivas regiões por meio do atendimento das vocações regionais e o despertar de novas vocações. Concluiu "que o ensino superior influencia positivamente a distribuição de renda, a renda per capita, a formação da cidadania e, por consequência, o desenvolvimento econômico, científico, social e cultural da região em que atua" (HAWERROT, 1999, p. 148). Importante frisar que a universidade deve ser compreendida como uma instituição social. E, nesse sentido: "[...] significa que ela realiza e exprime de modo determinado a sociedade de que é e faz parte. Não é uma realidade separada e sim uma expressão historicamente determinada de uma sociedade determinada" (CHAUI, 2001, p. 35).

Muito embora o estado de Santa Catarina tenha um ensino superior capilarizado e bons índices, quando comparado com as demais unidades da federação, nem todos os segmentos têm acesso ao ensino superior:

No ano de 2012, foi instituído o Programa de Estímulo à Reestruturação e ao Fortalecimento das Instituições de Ensino Superior (PROIES), pela Lei Federal $n^{\circ} 12.688$, de julho de 2012, com o objetivo, conforme estabelecido no Art. 3ํㅡ, de assegurar condições para a continuidade das atividades de mantenedoras de Instituições de Ensino Superior privadas e, principalmente, a recuperação dos créditos tributários da União por meio da ampliação da oferta de bolsas de estudo integrais para estudantes de cursos de graduação nas IES que aderissem ao programa. Para tal, a IES deveria migrar para o Sistema Federal de Educação, antigo desejo do Ministério da Educação, em relação às IESFMC que se vinculam ao Sistema Estadual de Educação. Do conjunto de IES, apenas a Unesc e a Univali aderiram ao programa.

Pela Lei Federal no 12.881, de 12 de novembro de 2013, regulamentaram-se a definição, qualificação, prerrogativas e finalidades das Instituições Comunitárias de Educação Superior - ICES, disciplinando o Termo de Parceria e dando outras providências. Essa regulamentação representa uma conquista das IESFMC, na celebração de parcerias com o poder público, repasse de recursos para projetos de natureza comunitária e com objetivo principal de fomentar o desenvolvimento regional.

\section{CONCLUSÃO}

Próximo a completar cinquenta anos de existência, as IES municipais têm à sua frente uma série de desafios que se não superados poderão inviabilizar, reduzir sua relevância no cenário catarinense, enquanto propulsores do desenvolvimento Regional. Resumidamente, podemos destacar: a) solucionar as questões de natureza financeira que inviabilizam investimentos; b) conviver, agora não somente com a expansão da rede privada de ensino superior, mas também da rede pública federal; c) investir na qualificação docente e em 
programas de manutenção dos docentes nas IES; d) criar programas stricto sensu em que, efetivamente, tem sido gerada a pesquisa e direcioná-la à solução de problemas locais e regionais, demonstrando à sociedade a real necessidade de sua existência, não apenas na formação de graduados; e) articular em rede, o que permitirá ações de maior abrangência com custo diluído; f) enfrentar a expansão da iniciativa privada com padrões de qualidade no tripé, ensino, pesquisa e extensão; g) ampliar parcerias com a sociedade organizada.

\section{REFERÊNCIAS}

ALMEIDA, R. O papel das universidades no desenvolvimento regional. In: SEMINÁRIO, A UNIVERSIDADE E O DESENVOLVIMENTO REGIONAL, 1980, Fortaleza. Anais ... Fortaleza: Edições UFC, 1980. p. 31-51. 291p.

ASSOCIAÇÃO CATARINENSE DAS FUNDAÇÕES EDUCACIONAIS - ACAFE. 25 anos. Florianópolis: ACAFE, 1999. Disponível em: <www.acafe.org.br>. Acesso em: 20 mar. 2013.

BRASIL. Decreto no $\mathbf{6 . 0 9 6}$, de 24 de abril de 2007. Institui o programa de apoio a planos de reestruturação e expansão das universidades federais - Reuni. Brasília: DOU, 25 abr. 2007.

Lei no 4.024, de 20 de dezembro de 1961. Estabelece as diretrizes e bases da educação nacional. Brasília: DOU, 27 dez. 1961.

Lei no 5.540, de 28 de novembro de 1968. Fixa normas de organização e funcionamento do ensino superior e sua articulação com a escola média, e dá outras providências. Brasília: DOU, 29 nov. 1968.

Lei no 13.005, de 25 de junho de 2014. Aprova o Plano Nacional de Educação PNE e dá outras providências. Brasília: DOU, 26 jun. 2014.

CHAUI, M. S. Escritos sobre a universidade. São Paulo: UNESP, 2001.

CIMADON, A.; BRANCHER, A. Ensino superior. In: SANTA CATARINA. Conselho Estadual de Educação. Informe $\mathbf{3 0}$ anos. Florianópolis: Governo de Santa Catarina, 1992.

DINIZ, J. Empreendedorismo social e responsabilidade social. Revista Linha Direta: Educação por Escrito, Belo Horizonte, n. 130, pp. 40-1, 2009.

FEDERAÇÃO DAS INDÚSTRIAS DO ESTADO DE SANTA CATARINA. Santa Catarina em Dados / Unidade de Política Econômica e Industrial. Florianópolis: FIESC, 2012, 152p.

GODDARD, J. O papel das universidades no desenvolvimento regional. In: ORGANIZAÇÃO DAS NAÇÕES UNIDAS PARA A EDUCAÇÃO, A CIÊNCIA E A CULTURA - UNESCO. Declaração mundial sobre educação superior no século XXI: visão e ação - marco referencial de ação prioritária para a mudança e o desenvolvimento da educação superior. Piracicaba: UNIMEP, 1998. pp. 385-424.

HAWERROTH, J. L. A expansão do ensino superior nas universidades do sistema fundacional catarinense. Florianópolis: Insular, 1999.

LAUXEN, S. L. Universidade regional. In: MOROSINI, M. C. (Editora chefe). Enciclopédia de 
pedagogia universitária: glossário. Brasília: INEP, 2006. p. 238.

ORCI, C. Ensino superior eleva renda do trabalhador em mais de 200\%, diz IBGE. Revista Ensino Superior, Campinas, 24 maio 2013. Disponível em: $<$ http://www.revistaensinosuperior.gr.unicamp.br/notas/ensino-superior-eleva-renda-dotrabalhador-em-mais-de-200-diz-ibge>. Acesso em: 07 out. 2014.

ORGANIZAÇÃO PARA COOPERAÇÃO E DESENVOLVIMENTO ECONÔMICO - OCDE. Avaliação de políticas nacionais de educação estado de Santa Catarina. Florianópolis: OCDE, 2010.

RICHARDSON, R. J. Pesquisa social: métodos e técnicas. São Paulo: Atlas, 1999.

SANTA CATARINA. Secretaria da Educação. Plano estadual de educação: quadriênio 1980/1983. Florianópolis: IOESC, 1980.

SERVIÇO DE APOIO ÀS MICROS E PEQUENAS EMPRESAS DE SANTA CATARINA SEBRAE/SC. Santa Catarina em números. Florianópolis: SEBRAE/SC, 2010. 127p.

VALENTE, I. Plano Nacional de Educação. Rio de Janeiro: DP\&A, 2001.

ZÖLLNER, N. Universidade e desenvolvimento regional. Jornal Vale Paraibano. 22 out. 2003. 